\title{
Effects of Inhomogeneities on Heat and Mass Transport Phenomena in Thermal Bridges
}

\author{
Paola Iodice ${ }^{1}$, Nicola Massarotti ${ }^{2}$ and Alessandro Mauro ${ }^{2, *}$ \\ 1 Università Telematica Pegaso, Centro Direzionale, Isola A3, 80143 Napoli, Italy; paola.iodice@unipegaso.it \\ 2 Dipartimento di Ingegneria, Università degli Studi di Napoli "Parthenope", Centro Direzionale, Isola C4, \\ 80143 Napoli, Italy; massarotti@uniparthenope.it \\ * Correspondence: alessandro.mauro@uniparthenope.it; Tel.: +39-081-547-6789 \\ Academic Editor: Vasily Novozhilov \\ Received: 10 November 2015; Accepted: 3 February 2016; Published: 26 February 2016
}

\begin{abstract}
The interest of calculating the effects of thermal bridges in buildings energy consumption is growing, due to recent energy saving regulations applied in different countries. The widespread use of insulating materials to reduce energy requirements of buildings, often employed for intermediate insulation of the building envelope, makes thermal bridges a crucial point in the energy analysis of building envelopes. Furthermore, heat losses through thermal bridges often lead to building pathologies due to moisture condensation. Therefore, thermal bridges need to be correctly characterized in the building design stage in order to reduce heat losses and avoid materials degradation. The authors numerically simulate, by using finite elements, the steady-state and dynamic three-dimensional (3D) heat and vapor transport in inhomogeneous thermal bridges and building envelopes. The aim of the present work is to show the importance of taking into account the presence of inhomogeneities (i.e., metal stud) in building materials for the calculation of actual heat losses and water condensation in 3D thermal bridges. The obtained heat transfer results are verified against the reference data of the technical standard UNI EN ISO 10211. The proposed microscopic approach is essential to calculate the actual heat losses of three-dimensional thermal bridges and building envelopes and to overcome condensation problems.
\end{abstract}

Keywords: inhomogeneity; dynamic; conduction; diffusion; thermal bridge; thermal dispersions

\section{Introduction}

The concept of energy saving includes a variety of techniques aimed at reducing the energy consumption needed for the different human activities. Nowadays, a great deal of attention has been given to efficient energy use in the heating and cooling sector, and building envelopes play a crucial role in the reduction of the energy consumption and the related costs. In fact, building heating and cooling are responsible for about $40 \%$ of the final energy consumption in the European Union (EU) and, as a consequence, for a considerable amount of total $\mathrm{CO}_{2}$ emissions [1]. The attention to the issue of energy efficiency in buildings is demonstrated by international and national directives [2-5], which describe the procedure for energy certification of buildings, and require member states to ensure that new and existing buildings meet minimum energy performance requirements, monitoring the actual energy demand or the estimated energy necessary to meet the various needs related to standard building uses, such as heating and cooling.

In this perspective, the methodology used to calculate the heat losses through the building envelope plays a crucial role, as well as the correct determination of the constitutive properties of the materials used. In many cases, one-dimensional and two-dimensional models do not correctly 
reproduce the heat transfer and vapor diffusion through the components of the building enclosure, but it is necessary to employ three-dimensional numerical models capable of solving the partial differential equations through the actual building envelope, characterized by the presence of geometric and structural non-uniformities, defined as thermal bridges.

These, characterized by a multi-dimensional heat flow and a consequent lowering of internal surface temperatures, are also those structures in which condensation and mold growth phenomena occur, due to incorrect design of the building envelope from the hygrothermal point of view. In this regard, the verification of hygrothermal performance [6] has the purpose of determining the possible presence of water condensed in a part of the examined structure, and then proceed to its correct design in order to avoid such critical phenomenon. Despite the requirements concerning the insulation of buildings, specified by national and international regulations, thermal bridges are a weak spot in constructions, since are often not dealt with properly. For example, the presence of inhomogeneities (i.e., metal stud) inside construction materials is often not taken into account, despite the consequent results could be very different, as shown in this work. These aspects lead to underestimate the heat losses during the design stage, therefore providing lower insulation levels for the building envelope, with consequent higher actual energy consumption, if compared to the estimates [7]. It should be pointed out that the use of different calculation methods of thermal bridges, provided in standards [8,9], can lead to different energy performance classes of a building and to percentage gaps on the energy requirements in the heating season, calculated to be more than $20 \%$ [10].

In this scenario, the use of numerical tools, required by the standards for the characterization of thermal bridges [9], should be extended to the verification of hygrothermal performance of these structures, given the complexity of solving the governing equations analytically. In these analyses, the thermal and hygrometric properties employed for each material of the building envelope assume a crucial role. These properties are available for most building components [11-13], or must be certified by the manufacturer and are commonly used in design calculations. However, problems may arise for inhomogeneous materials, such as concrete, heavily used in the existing building envelopes. In fact, the presence of steel stud strongly influences the thermal conductivity and the hygrometric properties of the inhomogeneous concrete structure. The adoption of the value of thermal conductivity of simple concrete may cause significant errors in the calculation of the actual heat losses. Furthermore, neglecting the presence of the metal stud, some areas of possible water condensation may be ignored, thus preventing the subsequent corrective action.

Therefore, the authors' aim in this work is to show the importance of taking into account the presence of inhomogeneities inside construction materials. This approach, referred to as "microscopic", requires to reproduce the inhomogeneities (i.e., metal stud), with their physical properties, inside the geometry under investigation.

The present paper is structured as follows: the next section provides a review of the available literature on numerical modelling of thermal bridges, and introduces the novelties of the present paper, then the mathematical model employed is described in section three. The fourth section shows the influence of the inhomogeneities inside building structures, while the fifth section reports the verification of the obtained results for a benchmark problem. The sixth section presents the main results obtained for the three-dimensional thermal bridge taken into account and for a room envelope, while some conclusions are drawn in the last section.

\section{Review of the Available Literature}

The importance of quantifying the heat loss through thermal bridges is well recognized in engineering practice, and technical standards provide a way to approximate the behavior of thermal bridges under steady design conditions. However, in order to take into account actual transient conditions, a number of works have studied thermal behavior of linear thermal bridges, to analyze their contribution to the total energy performance of buildings. The phenomenon depends on several factors, such as external and internal conditions, level of insulation, geometry of the thermal bridge 
and materials used, structure and use of building, and the results of calculations, unlike reality, often depend on the model used to calculate its effects on building energy demand [14]. Therefore, estimates of the actual weight of thermal bridges on the energy demand of buildings can vary from $5 \%$, in the case of retrofitting the exterior of the building envelope, to $39 \%$ in well insulated single family houses without proper thermal bridge treatment [14].

Due to the complexity of three-dimensional (3D) unsteady simulations, most studies use one-dimensional (1D) and two-dimensional (2D) approaches or steady-state regime. A review of methods for dynamic modelling of thermal bridges in building envelopes is reported in [15]. Moreover, most commercial software for the dynamic simulation of thermal performance of buildings assume 1D heat transfer neglecting 2D dynamic heat conduction through the thermal bridges of building enclosures [16].

An earlier work of Kosny and Christian [17] showed that thermal resistance of a concrete wall reinforced with metal stud may decrease of about $48 \%$ because of the steel-concrete thermal bridge effects. The authors employed a finite difference algorithm for the simulation of transient heat transfer in building walls and wall corners. Moreover, Kosny and Kossecka [18] demonstrated, by using a 3D finite difference algorithm, that the thermal resistance of walls, calculated neglecting the thermal bridge effects and adopting the one-dimensional approach, might be overestimated of more than $44 \%$. Gao et al. [16] used a reduction technique to simulate three-dimensional heat transfer. The work focused on the study of the dynamic behavior of thermal bridges in a simplified form by using a commercial simulation software. The study showed that thermal bridges are responsible for an increase in the overall heat loss of the building taken into account from 9\% to 19\%. Mao and Johannesson [19] developed a code based on a frequency response approximation method to calculate temperatures and heat fluxes in thermal bridges, by using the finite element discretization technique. Déqué et al. [20] integrated a 2D dynamic modeling of thermal bridges into a commercial software, showing that this approach can lead to a difference of $7 \%$ in heat losses evaluated with the use of tabulated values. An interesting 3D numerical study on the influence of outdoor environmental conditions on building energy performance has been carried out by He et al. [21] by using a proprietary algorithm, but neglecting the presence of thermal bridges in the building envelope. Recently, Tadeu et al. [1] proposed a 2D dynamic model, based on the boundary element method in the frequency domain, to characterize wall corners and estimate their influence on the thermal performance of building components. Theodosiou et al. [22] carried out 3D heat transfer simulations of cladding systems for building facades, showing that neglecting the point thermal bridge effect in these kind of systems can lead to a significant underestimation (from $5 \%$ to $20 \%$ ) of actual heat flows.

Some combined experimental and numerical works are also available in the literature. Nussbaumer et al. [23] analyzed both experimentally and numerically a concrete wall with external insulation of polystyrene boards, containing vacuum insulation panels, demonstrating the thermal improvement obtainable with this type of insulation. Wakili et al. [24] reproduced numerically, with a 3D commercial code, steady-state temperature field in a balcony board with integrated glass fiber reinforced plastic elements. Numerical results, combined with experimental data, proved that a reduction of heat losses are obtainable by using glass fiber reinforced elements instead of conventional steel rods. Zalewski et al. [25] employed a 3D commercial code for steady state analysis of thermal efficiency of complex building walls, focusing on the estimation of heat losses from thermal bridges. The authors also carried out an experimental analysis by using infrared thermography and heat flow meters for quantitative characterization of the losses through the envelope. A recent work by Lorenzati et al. [26] investigated the influence of thermal bridges on the overall energy performance of Vacuum Insulation Panels (VIP). They showed that the use of equivalent values for thermal conductivity of VIP could lead to significant errors in the estimation of thermal bridges' effects.

The above literature review proves the technical-scientific interest for the calculation of heat losses through thermal bridges, given the significant influence that these components of a building have on the global heat losses of buildings. To the authors' knowledge, some aspects on this subject are not 
dealt with in depth in the available literature. In particular, the above literature review shows that a microscopic approach that takes into account the presence of inhomogeneities inside construction materials has not been employed coupled with 3D numerical simulations of thermal bridges under dynamic conditions. Furthermore, the verification of hygrothermal performance in presence of inhomogeneous materials, which is a crucial aspect for building structures, has not been extended to $3 \mathrm{D}$ thermal bridges. On the basis of these considerations, in this work the authors, experienced in the field of numerical simulation of complex thermo-fluid-dynamics problems and energy saving systems [27-30], investigate the influence of inhomogeneities inside construction materials simulating transient heat conduction and vapor diffusion in 3D thermal bridges.

\section{Mathematical Model}

The mathematical model employed in the present work for the simulation of heat and mass transfer through a three-dimensional thermal bridge consists in the unsteady conservation equations for mass and energy in a homogeneous permeable medium. The governing equations have been solved by using the software Comsol Multiphysics. To employ the present microscopic approach, the governing equations are therefore written for each isotropic homogeneous material that is found in a typical building envelope:

Heat transfer by conduction

$$
\rho c \frac{\partial T}{\partial \vartheta}=\lambda \nabla^{2} T
$$

Vapor diffusion

$$
\frac{\partial p_{v}}{\partial \vartheta}=\delta \nabla^{2} p_{v}
$$

Therefore, in order to take into account the presence of metal stud in the thermal bridge, Equation (1) is also solved in the domain occupied by the metal.

The set of partial differential Equations (1) and (2) are solved with the following boundary and initial conditions for energy and mass:

$$
\begin{aligned}
& T(x, y, z, \vartheta=0)=T_{0} ; \quad p_{v}(x, y, z, \vartheta=0)=p_{v, 0} \quad \text { in the whole computational domain } \\
& h_{c, i}\left[T_{\infty, i}-T_{P, i}(x, y, z, \vartheta)\right]=-\left.\lambda \frac{\partial T(x, y, z, \vartheta)}{\partial n}\right|_{P, i} ; \quad p_{v}=p_{v, i} \quad \text { on the interior surfaces } \\
& h_{c, e}\left[T_{\infty, e}-T_{P, e}(x, y, z, \vartheta)\right]=-\left.\lambda \frac{\partial T(x, y, z, \vartheta)}{\partial n}\right|_{P, e} ; \quad p_{v}=p_{v, e} \quad \text { on the exterior surfaces } \\
& \left.\frac{\partial T(x, y, z, \vartheta)}{\partial n}\right|_{P}=0 ;\left.\quad \frac{\partial p_{v}(x, y, z, \vartheta)}{\partial n}\right|_{P}=0 \quad \text { on the lateral surfaces }
\end{aligned}
$$

where $T_{0}$ and $p_{v, 0}$ are the initial temperature and partial pressure of vapor, respectively, $h_{c, i}$ and $h_{c, e}$ are the convective heat transfer coefficients of the interior and exterior environment, respectively, $T_{\infty, i}$ and $T_{\infty, e}$ are the interior and exterior environment temperatures, respectively. $T_{P, i}$ and $T_{P, e}$ are the temperatures of the interior and exterior surfaces, respectively, $p_{v, i}$ and $p_{v, e}$ are the partial pressures of vapor in the interior and exterior environment. The mathematical model described above is solved by using the well known Finite Element Method [31,32].

The procedure for the verification of the hygrometric performance (Glaser's method), based on the technical standard [6], is here applied to thermal bridges. In order to avoid interstitial and superficial water condensation, the following condition must be satisfied in each point of the structure:

$$
p_{v}<p_{\text {sat }}(T)
$$


where $p_{\text {sat }}(T)$ is the saturation pressure of water at temperature $T$.

The relation between temperature and saturation pressure of water is given in [6] as:

$$
\begin{aligned}
& p_{\text {sat }}(T)=610.5 e^{\left(\frac{17.269 \cdot T}{237.3+T}\right)} \text { for } T \geqslant 0{ }^{\circ} \mathrm{C} \\
& p_{\text {sat }}(T)=610.5 e^{\left(\frac{21.875 \cdot T}{265.5+T}\right)} \text { for } T<0^{\circ} \mathrm{C}
\end{aligned}
$$

in which the temperature must be expressed in degrees Celsius $\left({ }^{\circ} \mathrm{C}\right)$.

In common practice, the conditions characterized by a vapor partial pressure, $p_{v}$, larger than saturation pressure of water at a prescribed temperature, $p_{\text {sat }}(T)$, are not physical, because saturation pressure is the maximum vapor pressure compatible with the prescribed temperature value, $T$. Therefore, inside the computational domain, wherever $\left[p_{v}-p_{\text {sat }}(T)\right] \geqslant 0$, condensation occurs. The Glaser's method applied to one-dimensional problems, such as those assumed in most building walls, allows to calculate the amount of water condensed in the wall as the difference between diffusive vapor flux entering and leaving the different layers of the wall [33,34]. This same type of analysis can be extended to three-dimensional problems, where condensation occurs in a volume delimited by surfaces (defined as $A$ and $B$ in the followings) on which the condition $\left.\left[p_{v}-p_{s a t}(T)\right]\right|_{A, B}=0$ is verified, while inside the volume the condition $\left[p_{v}-p_{\text {sat }}(T)\right] \geqslant 0$ occurs. Based on these considerations, the present numerical procedure is developed in order to estimate the rate of condensing water, $\dot{m}_{w}$, in a three-dimensional structure when condition Equation (4) is not verified, from the difference between the calculation of vapor flux and vapor flux at saturation conditions, as follows:

$$
\dot{m}_{w}=\left.g_{v}\right|_{A}-\left.g_{s a t}\right|_{B}
$$

where $\left.g_{v}\right|_{A}$ is the diffusive vapor flux entering the condensation volume through surface $A$, while $\left.g_{s a t}\right|_{B}$ is the diffusive vapor flux calculated at saturation conditions leaving the condensation volume through surface $B$ :

$$
\begin{gathered}
\left.g_{v}\right|_{A}=-\delta \int_{A} \nabla p_{v} \cdot n d A \\
\left.g_{\text {sat }}\right|_{B}=-\delta \int_{B} \nabla p_{\text {sat }}(T) \cdot n d B
\end{gathered}
$$

where surfaces $A$ and $B$ cannot be defined a-priori, since they depend on the temperature distribution in the considered geometry.

\section{Influence of Inhomogeneities inside Building Structures}

Materials employed in building applications are commonly considered to be homogeneous and isotropic, and their thermal properties are often dependent on temperature and density. However, when inhomogeneous and anisotropic media are taken into account, the physical properties are different because of the inhomogeneities present inside the material.

In this section, the authors take into account two typical constructive elements: a concrete pillar with metal stud and a brick-concrete slab, in order to analyze the influence of the inhomogeneities on the heat flux transferred by these structures. The first case is presented in Figure 1, which shows the three-dimensional profile of a concrete pillar $\left(0.3 \times 0.5 \times 3 \mathrm{~m}^{3}\right)$ with and without the metal stud, together with section and stud details. Two different stirrup spacing are taken into account, $0.2 \mathrm{~m}$ and $0.1 \mathrm{~m}$, in order to show the dependence of the heat flux on the construction characteristics. The materials considered are: (i) concrete of natural aggregates with closed structure and with a thermal conductivity $\lambda_{c o}=1.2 \mathrm{~W} /(\mathrm{m} \cdot \mathrm{K})$; (ii) steel, used as metal stud, with a thermal conductivity $\lambda_{s}=50 \mathrm{~W} /(\mathrm{m} \cdot \mathrm{K})$ [11-13]. In order to calculate the heat flux transferred by different pillar 
configurations, it is necessary to reproduce the problem numerically under steady-state and specified boundary conditions. The boundary conditions employed are:

$$
\begin{aligned}
& -\lambda \frac{\partial T}{\partial n}=h_{c, i}\left(T_{\infty, i}-T_{P, i}\right) \quad \text { with } \quad h_{c, i}=7.7 \mathrm{~W} /\left(\mathrm{m}^{2} \cdot \mathrm{K}\right) ; T_{\infty, i}=20^{\circ} \mathrm{C} \quad \text { on the interior surface } \\
& -\lambda \frac{\partial T}{\partial n}=h_{\mathcal{c}, e}\left(T_{\infty, e}-T_{P, e}\right) \quad \text { with } \quad h_{\mathcal{c}, e}=25 \mathrm{~W} /\left(\mathrm{m}^{2} \cdot \mathrm{K}\right) ; T_{\infty, e}=2{ }^{\circ} \mathrm{C} \text { on the exterior surface } \\
& \frac{\partial T}{\partial n}=0 \text { on the lateral surfaces }
\end{aligned}
$$

where the convective heat transfer coefficients are taken from technical standard [35], while the interior temperature is provided in $[36,37]$. The value of the exterior temperature considered is the design value referred to the city of Napoli in Italy, given in the technical standard [38].

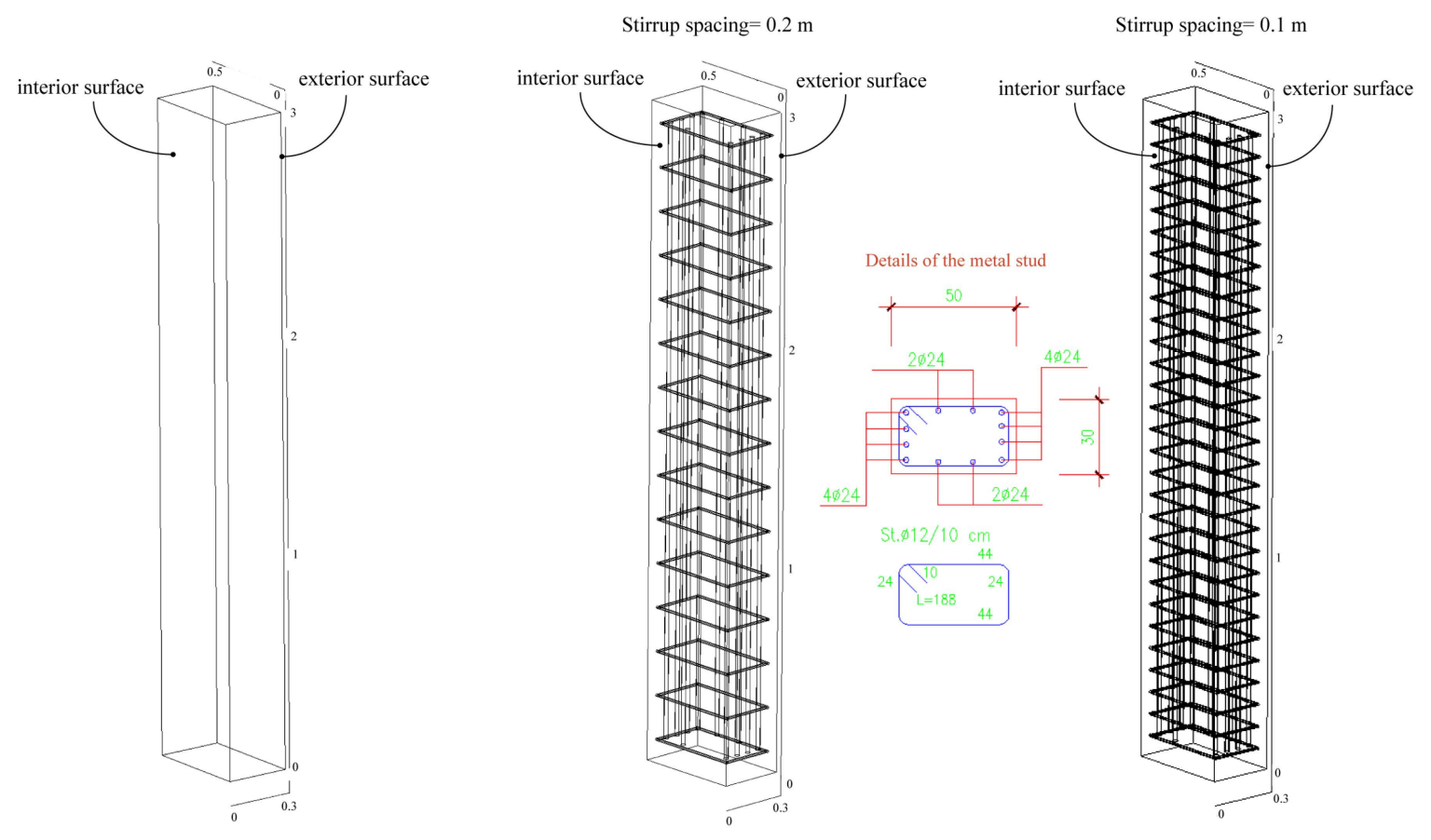

Figure 1. Three-dimensional profile of a concrete pillar $\left(0.3 \times 0.5 \times 3 \mathrm{~m}^{3}\right)$ without metal stud (left), with metal stud-stirrup spacing of $0.2 \mathrm{~m}$ (center), and with metal stud—stirrup spacing of $0.1 \mathrm{~m}$ (right).

The simulation of steady-state heat transfer allows to calculate, in the post-processing stage, the heat flux transferred from the exterior environment to the interior one. Table 1 reports the heat flux calculated for the three concrete pillar configurations. The presence of the metal stud in the concrete pillar leads to an increase of $6.8 \%$ of the heat flux if the metal stud with stirrup spacing of $0.2 \mathrm{~m}$ is considered, and $8.9 \%$ if the metal stud with stirrup spacing of $0.1 \mathrm{~m}$ is considered. From the analysis of the data presented in Table 1, it is evident that the presence of a steel stud in the concrete pillar has an influence on the heat flux transferred from the structure. This calculation should be carried out each time the amount of steel in the pillar changes.

The second case, presented in Figure 2, shows the three-dimensional profile of a concrete slab $\left(0.25 \times 1 \times 1.8 \mathrm{~m}^{3}\right)$ and of a brick-concrete slab, together with the details of the brick-concrete section. The materials considered are (i) concrete of natural aggregates with closed structure with a thermal conductivity $\lambda_{c o}=1.2 \mathrm{~W} /(\mathrm{m} \cdot \mathrm{K})$; (ii) steel rods with a thermal conductivity $\lambda_{s}=50 \mathrm{~W} /(\mathrm{m} \cdot \mathrm{K})$; (iii) bricks with a thermal conductivity $\lambda_{b}=0.4 \mathrm{~W} /(\mathrm{m} \cdot \mathrm{K})$ [11-13]. 
Table 1. Heat flux transferred from the different configurations of pillar and slab.

\begin{tabular}{|c|c|c|}
\hline & Heat flux & $\left(\mathrm{W} / \mathrm{m}^{2}\right)$ \\
\hline Concrete pillar & 42.9 & \\
\hline Concrete pillar with metal stud—stirrup spacing $0.1 \mathrm{~m}$ & 45.8 & \\
\hline Percentage difference & & $6.8 \%$ \\
\hline Concrete pillar with metal stud—stirrup spacing $0.2 \mathrm{~m}$ & 46.7 & \\
\hline Percentage difference & & $8.9 \%$ \\
\hline Concrete slab & 47.6 & \\
\hline Brick-concrete slab & 33.3 & \\
\hline Percentage difference & & $-30 \%$ \\
\hline
\end{tabular}

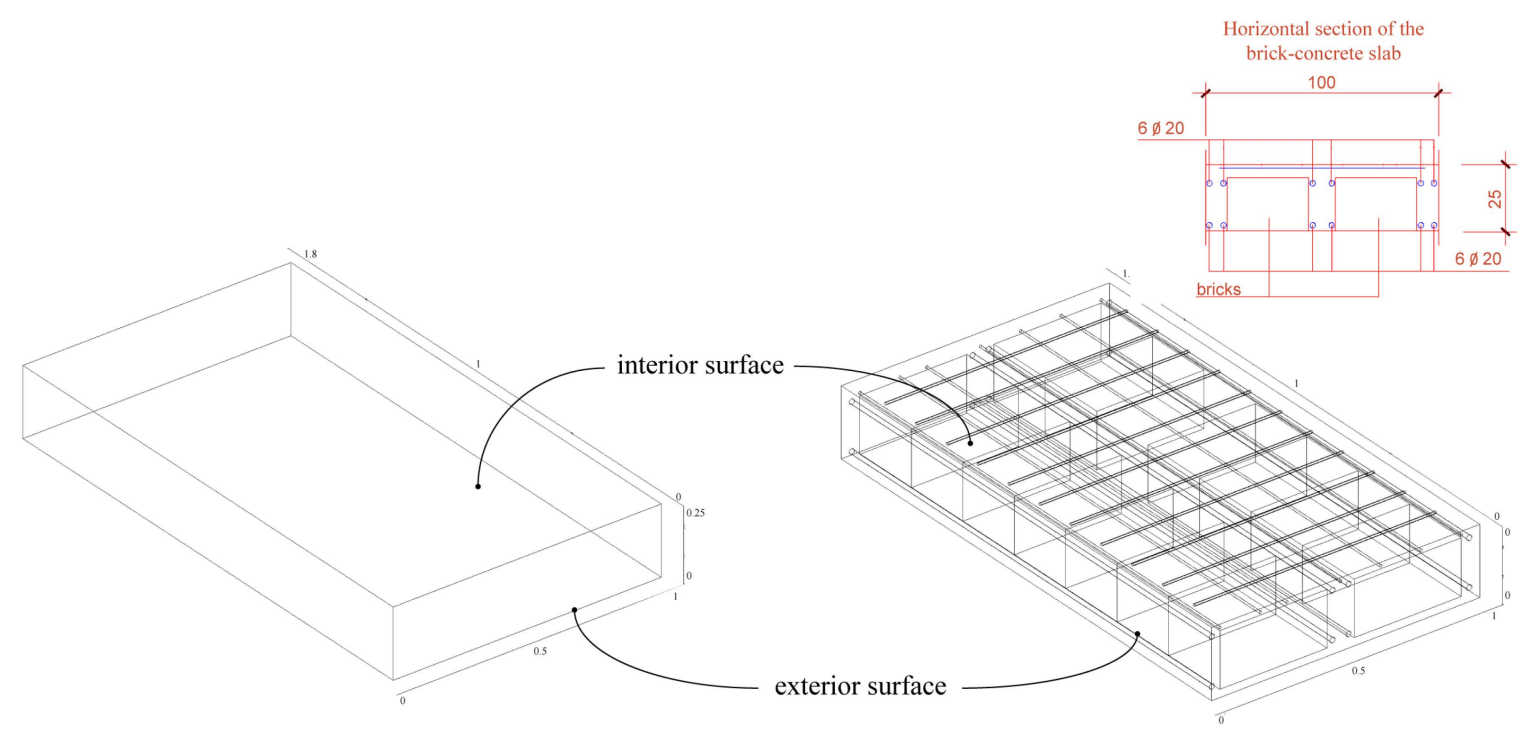

Figure 2. Three-dimensional profile of a concrete slab $\left(0.25 \times 1 \times 1.8 \mathrm{~m}^{3}\right)(\mathbf{l e f t})$ and of a brick-concrete slab (right).

The boundary conditions employed are represented by Equations (8). The values of heat flux calculated by means of numerical simulation are reported in Table 1. It should be pointed out that the presence of the bricks strongly influences the heat flux transferred from the interior to exterior surface of the slab. In fact, the value of this parameter decreases of $30 \%$ with respect to the case of pure concrete (Table 1).

These results highlight the difference in terms of heat flux due to the presence of inhomogeneities inside construction materials, by using a microscopic approach. However, in order to correctly characterize a building structure in terms of both heat transfer and vapor diffusion, unsteady simulations should be carried out. In addition, the presence of inhomogeneities must be necessarily taken into account, by using the present microscopic approach, as shown for the two configurations of thermal bridges and for the room envelope presented in Section 6. With this approach, the actual building structure is numerically reproduced, and the physical properties of the materials reported in the technical standards [11-13] are considered. Therefore, the use of non-physical parameters, such as equivalent values of physical properties, is avoided. Before showing these results, the required verification of the numerical model is presented in the next section.

\section{Verification of the Numerical Model}

The results obtained by using the present numerical model are verified against the reference data available in technical standard [9] for steady-state heat transfer through a three-dimensional thermal 
bridge. The geometry of the benchmark problem considered and the description of the surfaces with different boundary conditions are depicted in Figure 3. The computational domain consists of a three-dimensional structure that separates three environments kept at different temperatures. More details necessary for defining the geometry are available in reference [9]. The boundary conditions employed in the simulations, with reference to the surfaces highlighted in Figure 3, are:

$$
\begin{aligned}
& -\lambda \frac{\partial T}{\partial n}=h_{c, i 1}\left(T_{\infty, i 1}-T\right) \text { with } h_{c, i 1}=5 \mathrm{~W} /\left(\mathrm{m}^{2} \cdot \mathrm{K}\right) ; T_{\infty, i 1}=15^{\circ} \mathrm{C} \text { on the interior (green) surfaces } \\
& -\lambda \frac{\partial T}{\partial n}=h_{c, i 2}\left(T_{\infty, i 2}-T\right) \text { with } h_{c, i 2}=5 \mathrm{~W} /\left(\mathrm{m}^{2} \cdot \mathrm{K}\right) ; T_{\infty, i 2}=20^{\circ} \mathrm{C} \text { on the interior (blue) surfaces } \\
& -\lambda \frac{\partial T}{\partial n}=h_{c, e}\left(T_{\infty, e}-T\right) \quad \text { with } h_{c, e}=20 \mathrm{~W} /\left(\mathrm{m}^{2} \cdot \mathrm{K}\right) ; T_{\infty, e}=0^{\circ} \mathrm{C} \quad \text { on the exterior (pink) surfaces } \\
& \frac{\partial T}{\partial n}=0 \text { on the lateral (grey) surfaces }
\end{aligned}
$$

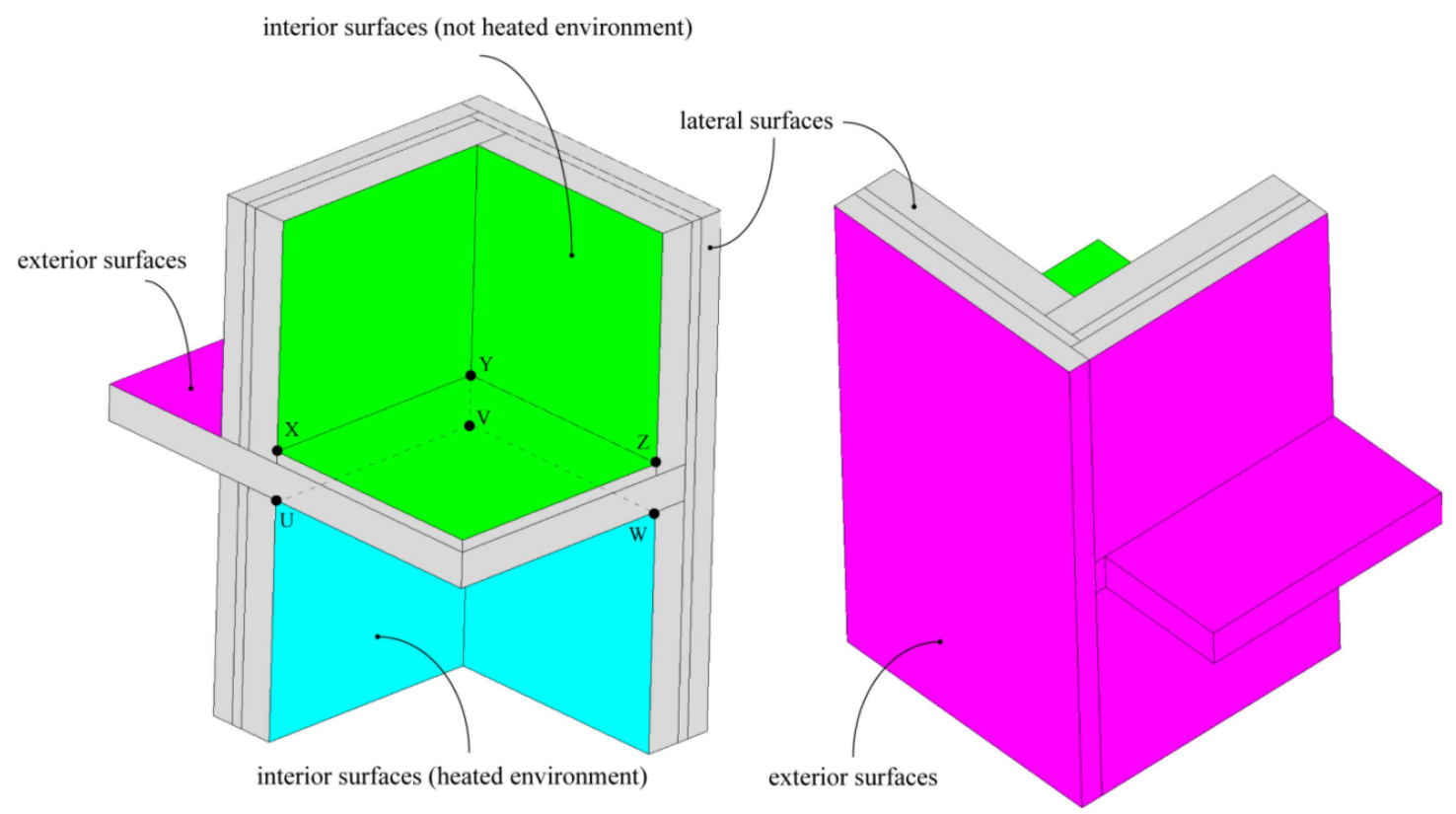

Figure 3. Computational domain considered: front view (left) and rear view (right) of the 3D thermal bridge.

The computational grid employed is made of 72010 nodes and 383715 tetrahedral elements. The mesh has been chosen after grid sensitivity analysis, in order to ensure that all the calculated values are mesh independent. Grid independency is considered to be achieved when the maximum difference between the quantities of interest calculated with a mesh and those obtained with the next finer grid is smaller than $1 \%$.

The verification of the results against reference data [9] is presented in Table 2. The points and surfaces considered for temperature calculation are reported in Figure 3. In order to consider the numerical model verified, the technical standard [9] requires a difference between the calculated temperatures and reference data to be less or equal to $0.1 \mathrm{~K}$, and a difference on the obtained heat flow rate and reference values less equal than $2 \%$. From the analysis of Table 2, it is evident that the present results are in perfect agreement with the data provided in [9], and the above requirements are verified. 
Table 2. Verification of the results against reference data [9].

\begin{tabular}{|c|c|c|c|}
\hline \multicolumn{4}{|c|}{ Temperature $\left({ }^{\circ} \mathrm{C}\right)$} \\
\hline Points & Present Solution & Reference Data [9] & Difference \\
\hline $\mathrm{U}$ & 12.90 & 12.90 & 0.00 \\
\hline $\mathrm{V}$ & 11.31 & 11.30 & 0.01 \\
\hline W & 16.41 & 16.40 & 0.01 \\
\hline$x$ & 12.56 & 12.60 & 0.04 \\
\hline $\mathrm{Y}$ & 11.08 & 11.10 & 0.02 \\
\hline Z & 15.28 & 15.30 & 0.02 \\
\hline \multicolumn{4}{|c|}{ Heat Flow Rate (W) } \\
\hline Surfaces & Present Solution & Reference Data [9] & Difference (\%) \\
\hline interior blue surfaces & 45.49 & 46.30 & 1.75 \\
\hline interior green surfaces & 13.81 & 14.00 & 1.36 \\
\hline exterior pink surfaces & 59.48 & 60.30 & 1.36 \\
\hline
\end{tabular}

\section{Numerical Results}

In the present work, the authors have simulated both steady-state and unsteady conduction heat transfer and diffusion of vapor in a three dimensional (3D) thermal bridge. The geometry considered for the numerical analysis is similar to the one proposed in the technical standard [9], opportunely modified to reproduce a structure adopted in actual constructions. In particular, a pillar $\left(0.3 \times 0.3 \times 2.3 \mathrm{~m}^{3}\right)$ is inserted at the corner, and the presence of interior and exterior plasters and of tiles is considered.

Furthermore, in order to show the importance of taking into account the presence of internal inhomogeneities of the materials employed in constructions to correctly estimate heat losses and condensation, two different cases are considered: the pillar and the slab are made of concrete of natural aggregates with closed structure (case 1); a steel stud in the pillar and a brick-concrete slab are considered (case 2). The 3D structures for the two cases of modified thermal bridge are reported in Figures 4 and 5 respectively, while the wall and slab sections are reported in Figure 6. The physical properties of the materials employed in the modified thermal bridge, taken from the technical standards [11-13], together with their geometrical characteristics, are reported in Table 3. The geometry of thermal bridge corresponding to case 2 is the same as that studied by one of the authors in a recent paper [39], where the aim was to analyze experimentally and numerically the effects of innovative materials employed in building structures.

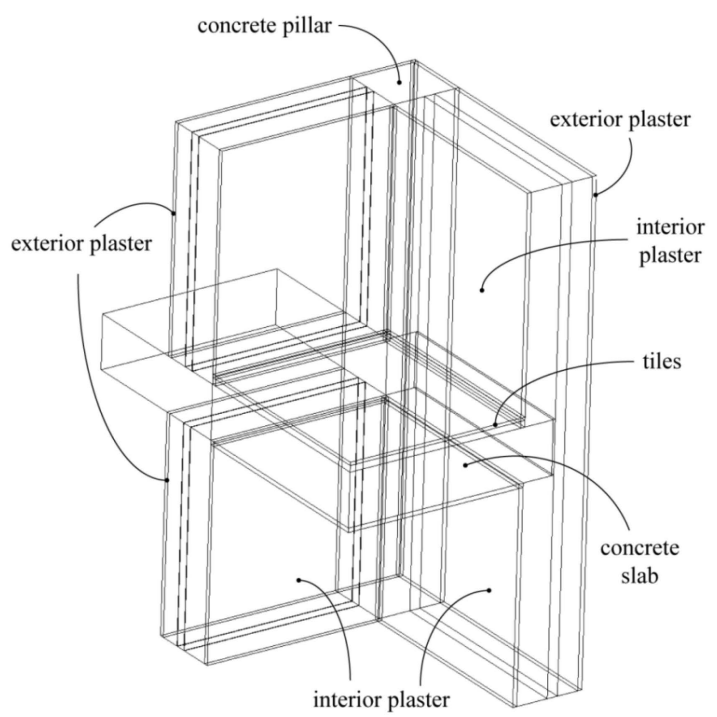

Figure 4. Three-dimensional profile of the modified thermal bridge with concrete pillar and slab (case 1). 

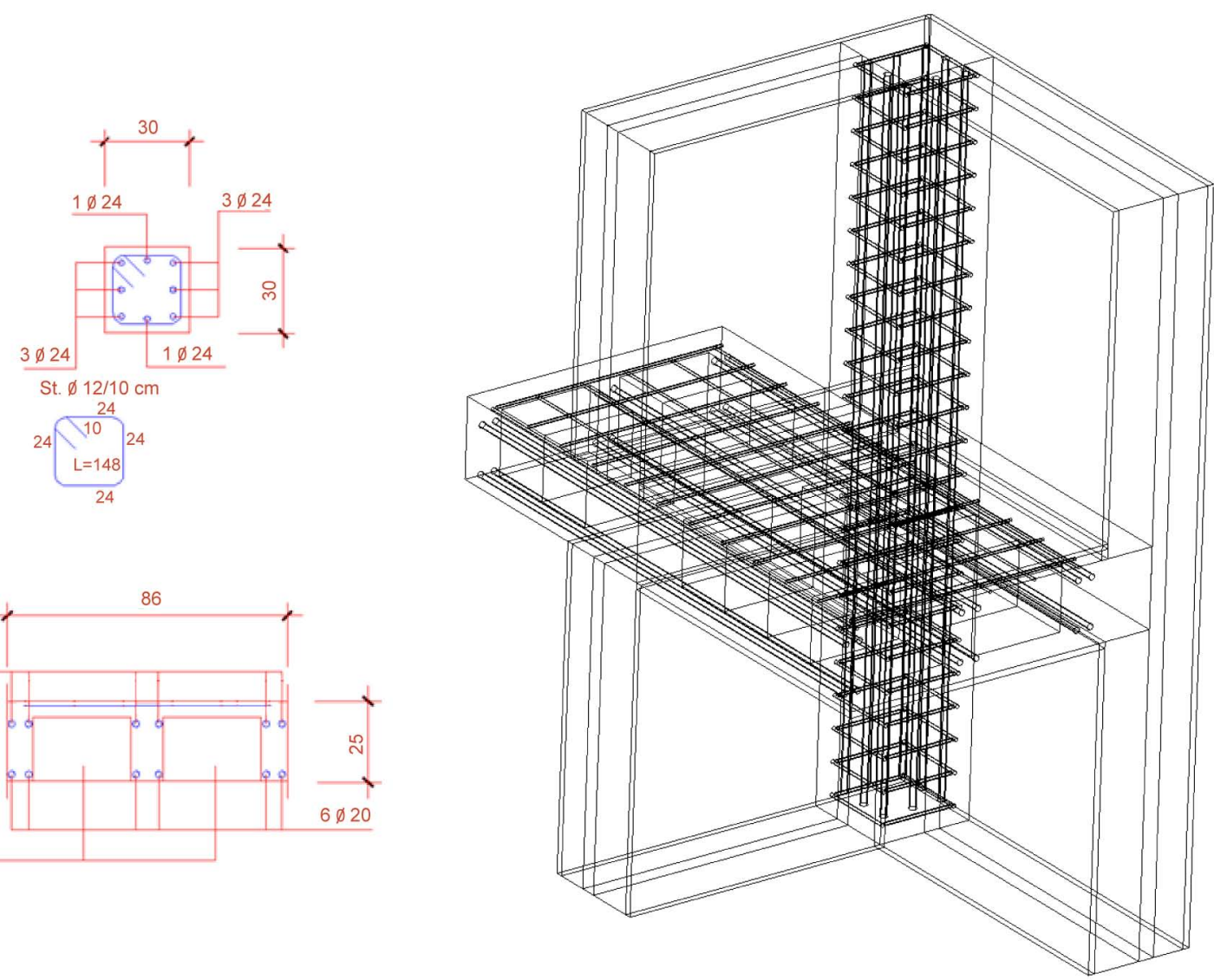

Figure 5. Three-dimensional profile of the modified thermal bridge with steel-concrete pillar and brick-concrete slab (case 2), with pillar and slab sections (left).
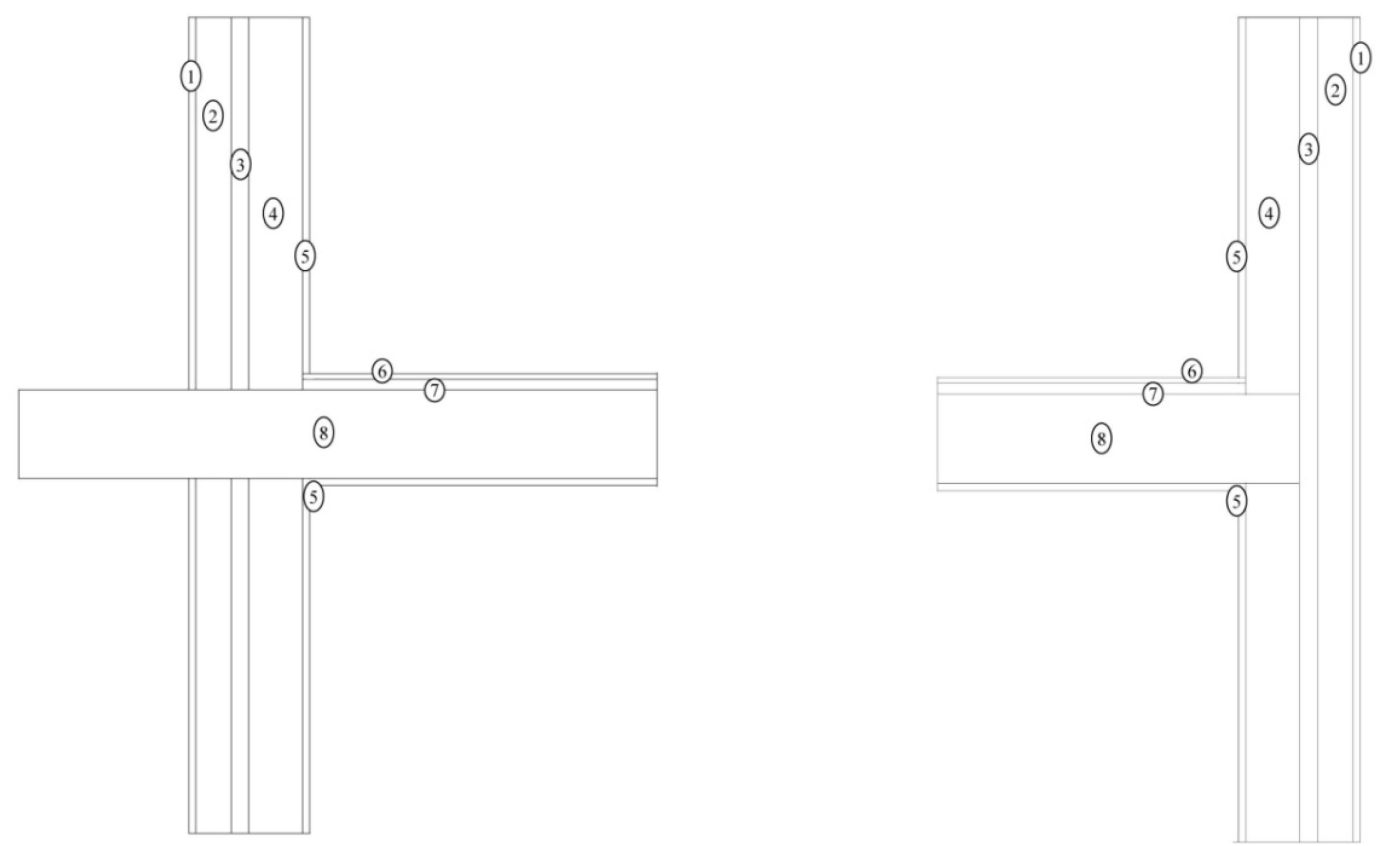

Figure 6. Longitudinal and transverse sections of the modified thermal bridge. 
Table 3. Properties of the materials employed in the modified thermal bridge.

\begin{tabular}{ccccccc}
\hline Material & Reference & $\begin{array}{c}\text { Conductivity } \\
\lambda \\
(\mathbf{W} /(\mathbf{m} \cdot \mathbf{K}))\end{array}$ & $\begin{array}{c}\text { Vapor } \\
\text { Permeability } \\
\delta \cdot 10^{12} \\
(\mathbf{k g} /(\mathbf{m} \cdot \mathbf{s} \cdot \mathbf{P a}))\end{array}$ & $\begin{array}{c}\text { Densiy } \\
\boldsymbol{\rho} \\
\left(\mathbf{k g} / \mathbf{m}^{3}\right)\end{array}$ & $\begin{array}{c}\text { Specific Heat } \\
\text { Capacity } \\
\boldsymbol{c} \\
(\mathbf{J} /(\mathbf{k g} \cdot \mathbf{K}))\end{array}$ & $\begin{array}{c}\text { Thickness } \\
\mathbf{s}\end{array}$ \\
\hline $\begin{array}{c}\text { Exterior } \\
\text { plaster }\end{array}$ & n.1-Figure 6 & 0.70 & 18 & 1400 & 1000 & 0.02 \\
\hline Solid brick & n.2-Figure 6 & 0.72 & 27 & 1800 & 840 & 0.10 \\
\hline Insulation & n.3-Figure 6 & 0.04 & 3.2 & 30 & 1250 & 0.04 \\
\hline Hollow brick & n.4-Figure 6 & 0.30 & 27 & 800 & 840 & 0.12 \\
\hline $\begin{array}{c}\text { Interior } \\
\text { plaster }\end{array}$ & n.5-Figure 6 & 0.35 & 18 & 1200 & 1000 & 0.02 \\
\hline Malta & n.7-Figure 6 & 0.90 & 9.0 & 1800 & 1000 & 0.03 \\
\hline Tiles & n.6-Figure 6 & 1.4 & 9.0 & 2300 & 840 & 0.015 \\
\hline Concrete-pillar & Figure 4 & 1.2 & 3.0 & 2000 & 1000 & 0.30 \\
\hline Concrete-slab & n.8-Figure 6 & 1.2 & 3.0 & 2000 & 1000 & 0.25 \\
\hline Steel-stud & Figure 5 & 52 & 0.0 & 7800 & 500 & Figure 5 \\
\hline
\end{tabular}

In addition to the 3D thermal bridge, the authors analyze numerically a room of an apartment located at the top floor of a building.

\subsection{Thermal Bridge under Steady-State Conditions}

The boundary conditions employed for the solution of steady-state heat transfer are represented by Equations (9), but with different values of $h_{c, i 1}, h_{c, i 2}, h_{c, e}: 7.7 \mathrm{~W} /\left(\mathrm{m}^{2} \cdot \mathrm{K}\right), 7.7 \mathrm{~W} /\left(\mathrm{m}^{2} \cdot \mathrm{K}\right)$ and $25 \mathrm{~W} /\left(\mathrm{m}^{2} \cdot \mathrm{K}\right)$, respectively, as required in technical standard [35]. The boundary conditions employed for the solution of steady-state vapor diffusion, referred to the same surfaces considered for heat transfer and highlighted in Figure 3, are:

$$
\begin{aligned}
& \left.p_{v, i 1}=852 \mathrm{~Pa} \text { (corresponding to } \phi_{i 1}=50 \%\right) \quad \text { on the interior (green) surfaces } \\
& p_{v, i 2}=1168 \mathrm{~Pa} \text { (corresponding to } \phi_{i 2}=50 \% \text { ) on the interior (blue) surfaces } \\
& p_{v, e}=366 \mathrm{~Pa} \text { (corresponding to } \phi_{e}=60 \% \text { ) on the exterior (pink) surfaces } \\
& \frac{\partial p_{v}}{\partial n}=0 \quad \text { on the lateral (grey) surfaces }
\end{aligned}
$$

From the obtained numerical results, reported in Table 4 in terms of the heat flux transferred by the interior and exterior surfaces of the thermal bridge, it is possible to appreciate significant differences between case 1 and case 2 . The difference on the heat flux calculated for case 1 and case 2 , due to the presence of inhomogeneities in case 2, reaches the $16 \%$. Obviously, these results depend on the geometry and on the construction characteristics of the structures considered in the simulations, and the percentage gap can increase for larger amount of steel or smaller bricks. Table 4 also reports the results obtained when the properties corresponding to reinforced concrete are used (case 1.b), taken from the technical standard [13]. In particular, a thermal conductivity of $2.5 \mathrm{~W} /(\mathrm{m} \cdot \mathrm{K})$ has been used in the simulations, instead of the value of $1.2 \mathrm{~W} /(\mathrm{m} \cdot \mathrm{K})$ reported in Table 3 . When the property value corresponding to reinforced concrete is considered, the differences with case 2 are larger with respect to the previous case 1. 
Table 4. Heat flux transferred by the interior and exterior surfaces and rate of condensed water for the two configurations of thermal bridge.

\begin{tabular}{lcccr}
\hline & & Heat Flux $\left(\mathbf{W} / \mathbf{m}^{2}\right)$ & & $\begin{array}{c}\text { Rate of Condensed } \\
\text { Water }\left(10^{-5} \mathbf{g} / \mathbf{s}\right)\end{array}$ \\
& $\begin{array}{c}\text { Interior Blue } \\
\text { Surfaces }\end{array}$ & $\begin{array}{c}\text { Interior Green } \\
\text { Surfaces }\end{array}$ & $\begin{array}{c}\text { Exterior Pink } \\
\text { Surfaces }\end{array}$ & Whole Structure \\
\hline Thermal bridge (case 1) & -14.1 & -6.3 & 7.7 & 3.31 \\
Thermal bridge (case 1.b) & -16.5 & -7.4 & 9.9 & 4.28 \\
Thermal bridge (case 2) & -14.9 & -7.3 & 8.5 & 3.71 \\
Percentage difference 1-2 & $5.7 \%$ & $-16 \%$ & & $10 \%$ \\
Percentage difference 1.b-2 & $-9.7 \%$ & $-1.4 \%$ & $-14 \%$ & $-13 \%$ \\
\hline
\end{tabular}

Moreover, from the analysis of Figure 7, which shows the temperature contours for the two thermal bridge configurations considered, it is clear that the temperature distribution in the thermal bridge is different in case 1 and case 2 . In fact, the inhomogeneities in the structure cause a temperature decrease, particularly evident on the lower floor (blue color in Figure 3), as shown in Figure 7, on the right. Table 4 reports the rate of water condensing in the thermal bridge, which increases by about $12 \%$ when inhomogeneities are taken into account.
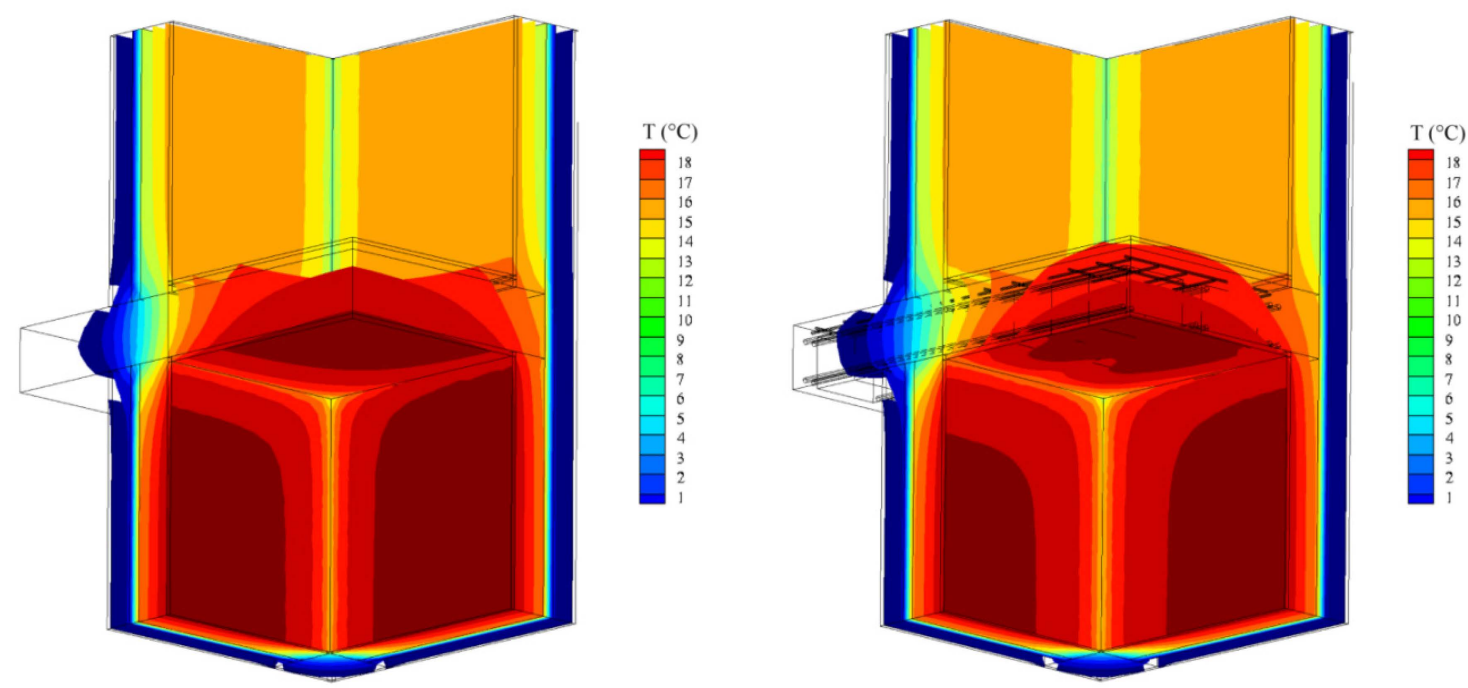

Figure 7. Temperature contours for case 1 (left) and case 2 (right) under steady state conditions.

\subsection{Thermal Bridge under Unsteady Conditions}

The two configurations of the thermal bridge, whose 3D profiles are reported in Figures 4 and 5 are also studied under unsteady conditions. In particular, the time-dependent exterior temperature and partial pressure of vapor are considered in the simulations. The vapor partial pressure is calculated on the basis of time-dependent relative humidity, $\phi(\vartheta)$, and time-dependent saturation pressure of water, $p_{\text {sat }}(T(\vartheta))$, as: $p_{v}(\vartheta)=\phi(\vartheta) p_{\text {sat }}(T(\vartheta))$. Therefore, the boundary conditions employed for the solution of transient heat transfer are the same of the previous section for the interior and lateral surfaces, while on the exterior surfaces are:

$$
-\lambda \frac{\partial T(\vartheta)}{\partial n}=h_{c, e}\left[T_{\infty, e}(\vartheta)-T_{P, e}(\vartheta)\right] \quad \text { with } \quad h_{c, e}=25 \mathrm{~W} /\left(\mathrm{m}^{2} \cdot \mathrm{K}\right)
$$

The boundary conditions employed for the solution of transient vapor diffusion are represented by Equations (10) for the interior and lateral surfaces, while on the exterior surfaces are:

$$
p_{\vartheta, e}=p_{v, e}(\vartheta)=\phi_{e}(\vartheta) \cdot p_{s a t}\left(T_{\infty, e}(\vartheta)\right)
$$


As initial conditions for both dynamic heat transfer and vapor diffusion, the solution obtained from the steady state simulations has been employed. The values of time-dependent exterior temperature, $T_{\infty, e}(\vartheta)$, and time-dependent relative humidity, $\phi_{e}(\vartheta)$, are calculated for the city of Aosta in Italy on the basis of the technical standard [40], that reports the methodology to be employed for the definition of the reference year to be used to reproduce the climatic conditions. One week hourly simulation has been carried out for the coldest week of the reference year, with temperature values ranging between $9.1^{\circ} \mathrm{C}$ and $-6.3^{\circ} \mathrm{C}$ (Figure 8).

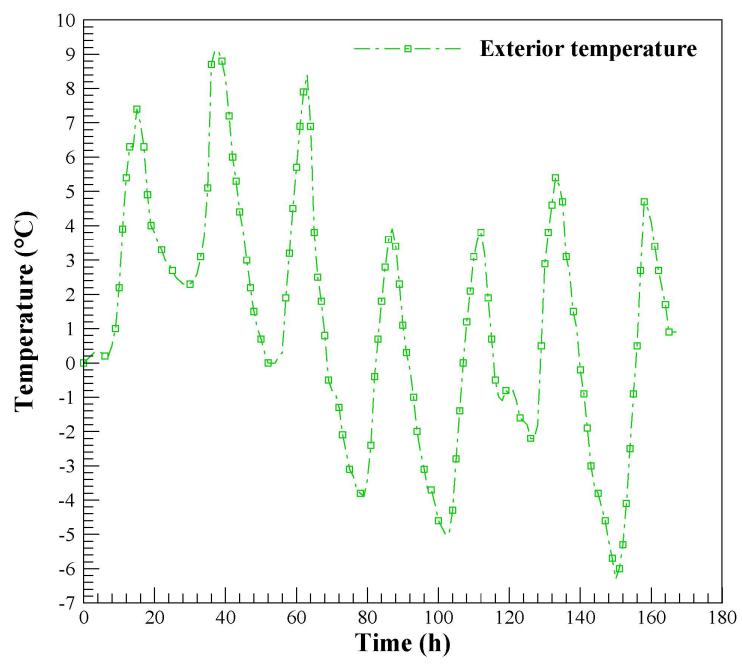

Figure 8. Exterior temperature.

Figure 9 reports the heat flux transferred from the interior surfaces of the two configurations of thermal bridge over the coldest week of the year for the city of Aosta. It is evident that the presence of inhomogeneities causes a different thermal behavior of the structure. In particular, the difference of heat flux between the two cases is almost constant during the week considered in the simulations, since the presence of insulation between the bricks dampens the oscillations of the exterior temperature.
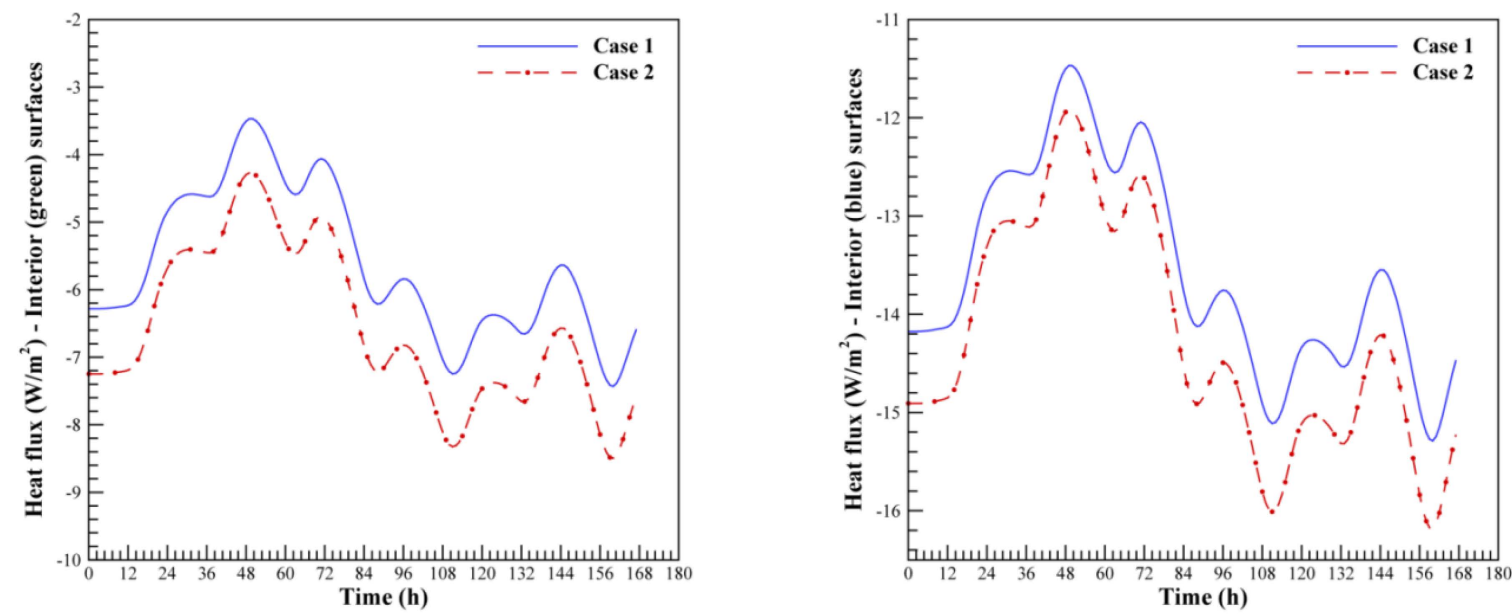

Figure 9. Heat flux transferred from the interior surfaces of the not-heated (left) and heated (right) environment.

Figures 10 and 11 show the temperature contours obtained for case 1 and case 2, respectively, at four different times $(12,48,96$ and $168 \mathrm{~h})$. From the analysis of these figures, it can be noticed that the 
temperature distribution in the two configurations of thermal bridge is significantly different at all the time instants presented, due to the inhomogeneities of case 2.

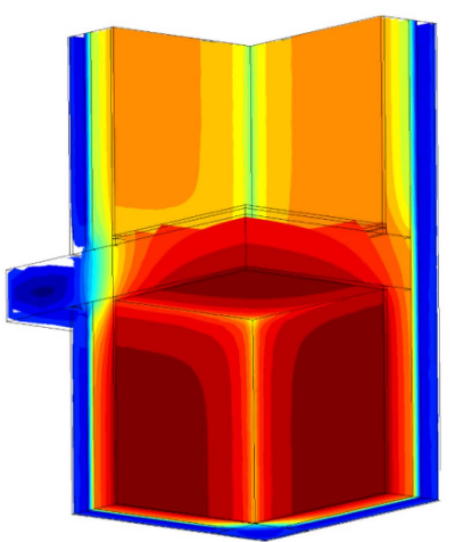

(a)

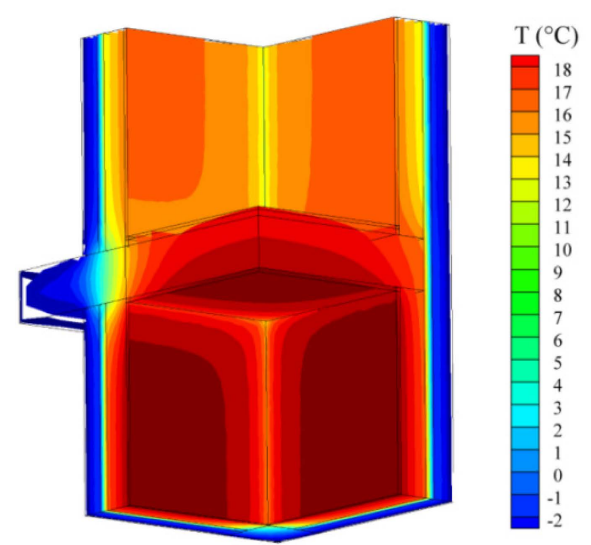

(c)

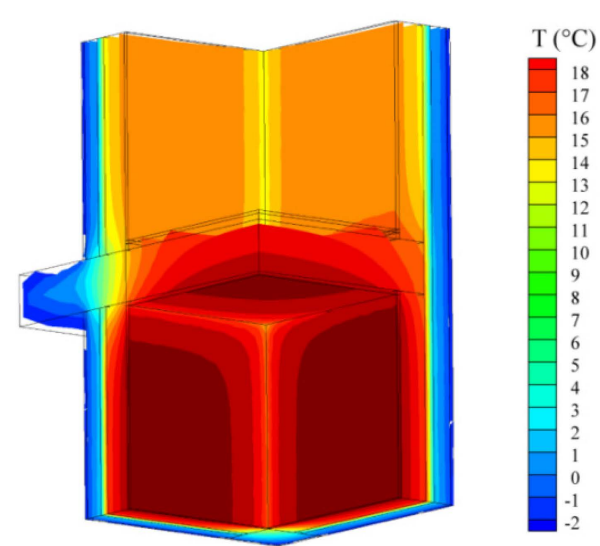

(b)

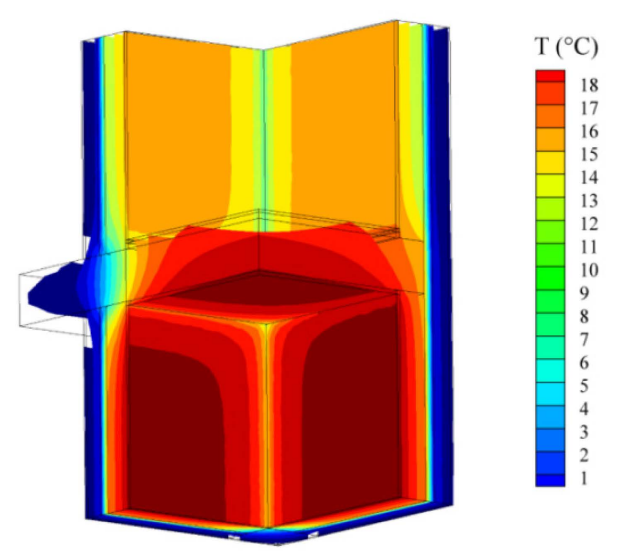

(d)

Figure 10. Temperature contours obtained for case 1 after: 12 h (a); 48 h (b); 96 h (c); 168 h (d).

Figure 12 shows the variation of temperature at point $\mathrm{V}$ of Figure 3 for the two cases of thermal bridge considered. This trend confirms the difference in the thermal behavior of the structure, introduced by the metal stud and the brick-concrete slab. Figure 12 also shows the rate of condensed water, $\dot{m}_{w}$, during the considered week. Only positive values of $\dot{m}_{w}$ are reported in Figure 12, meaning that condensation occurs in the structure. From the analysis of the figure, it is clear that the inhomogeneities present in the thermal bridge result in different amounts of condensed water, confirming the differences found in the steady-state simulations. 


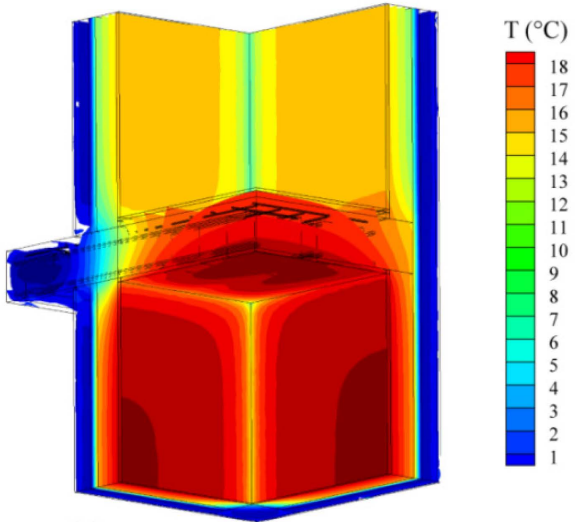

(a)

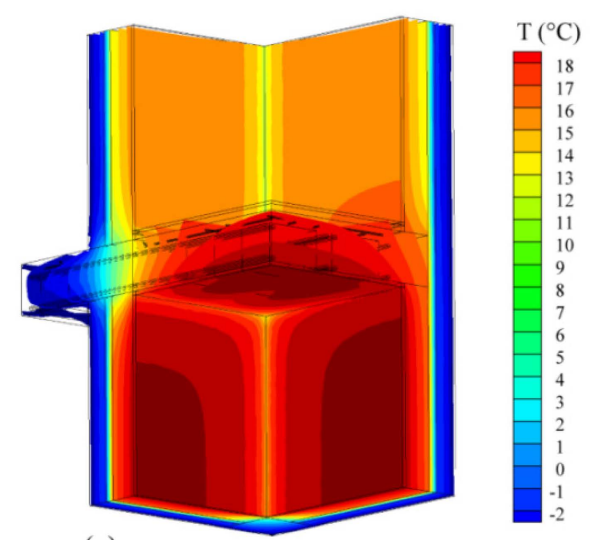

(c)

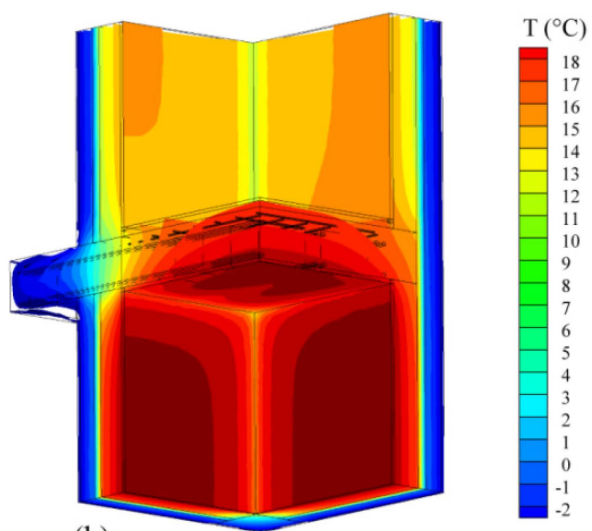

(b)

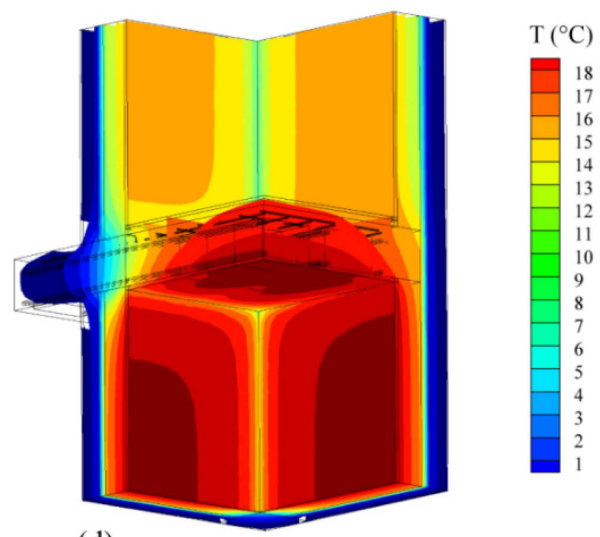

(d)

Figure 11. Temperature contours obtained for case 2 after: 12 h (a); 48 h (b); 96 h (c); 168 h (d).
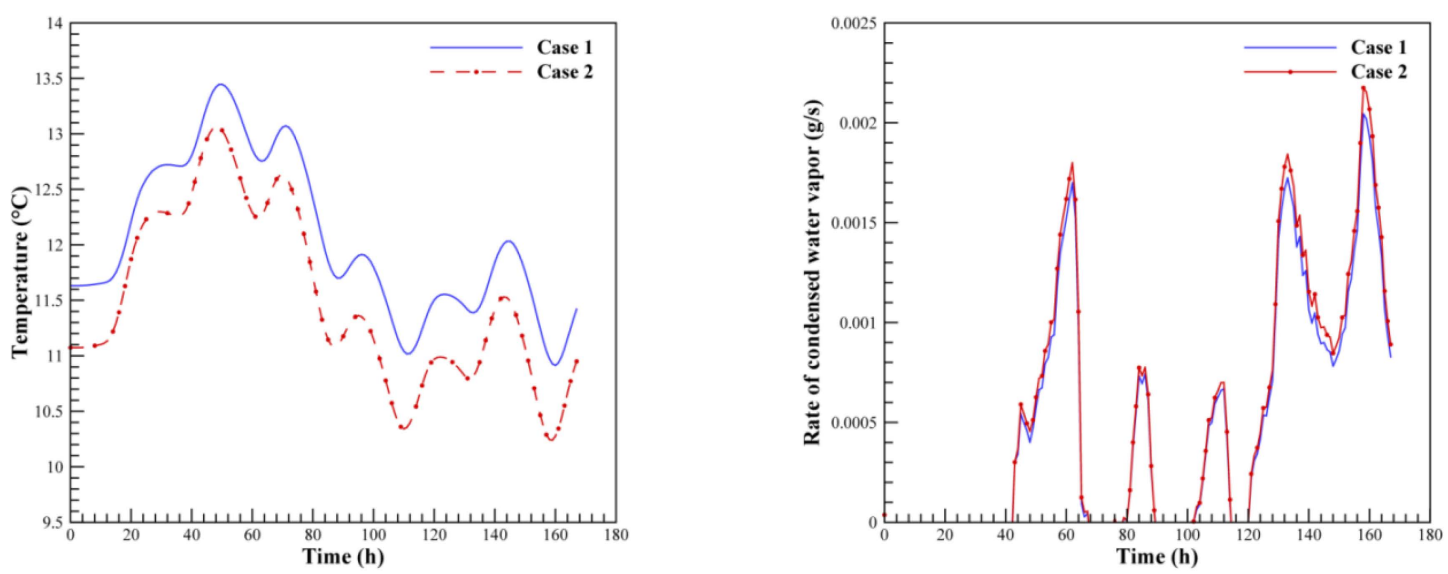

Figure 12. Temperature at point $V$ of Figure 3 (left) and rate of condensed water vapor in the structure (right) for the two configurations of thermal bridge.

\subsection{Building Envelope under Unsteady Conditions}

In order to prove the capability of the present numerical approach to integrate the behavior of 3D thermal bridges in the dynamic simulation of building structures, the geometry shown in Figure 13 has 
been studied under transient conditions. This geometry represents the room of an apartment located at the top floor of a building, with two exterior walls and the roof exposed to the environment conditions. Two single-glass windows with an aluminum frame have been considered. The steel-concrete pillar studied in the previous section has been employed at the corners of this structure.

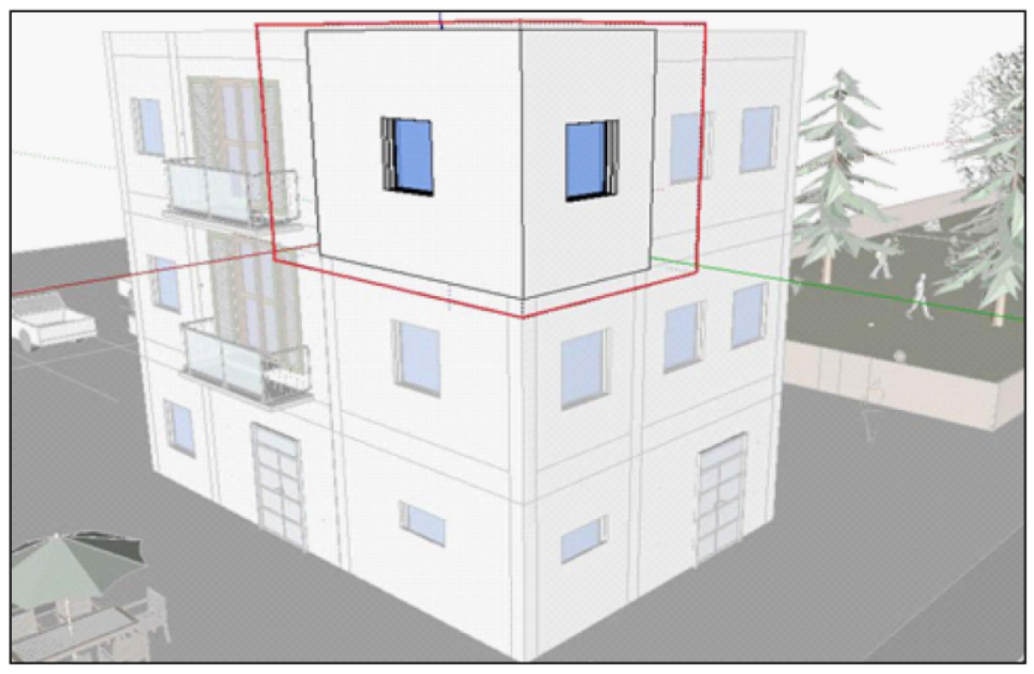

Figure 13. Three-dimensional building envelope.

Figure 14 reports the geometric characteristics of the room envelope taken into account in the simulations. The exterior thermal boundary conditions are represented by Equation (11), including also radiative heat transfer on opaque surfaces, while Equation (12) represents exterior boundary conditions for vapor diffusion. A temperature of $20{ }^{\circ} \mathrm{C}$, with a convective heat transfer coefficient equal to $7.7 \mathrm{~W} /\left(\mathrm{m}^{2} \cdot \mathrm{K}\right)$, and a vapor partial pressure of $1168 \mathrm{~Pa}$ have been considered as boundary conditions at the interior of the room. Since the whole building has been considered at the same constant interior temperature and relative humidity and, as a consequence, partial pressure of vapor, the vertical wall without window and the pavement have been considered adiabatic and impermeable to mass.
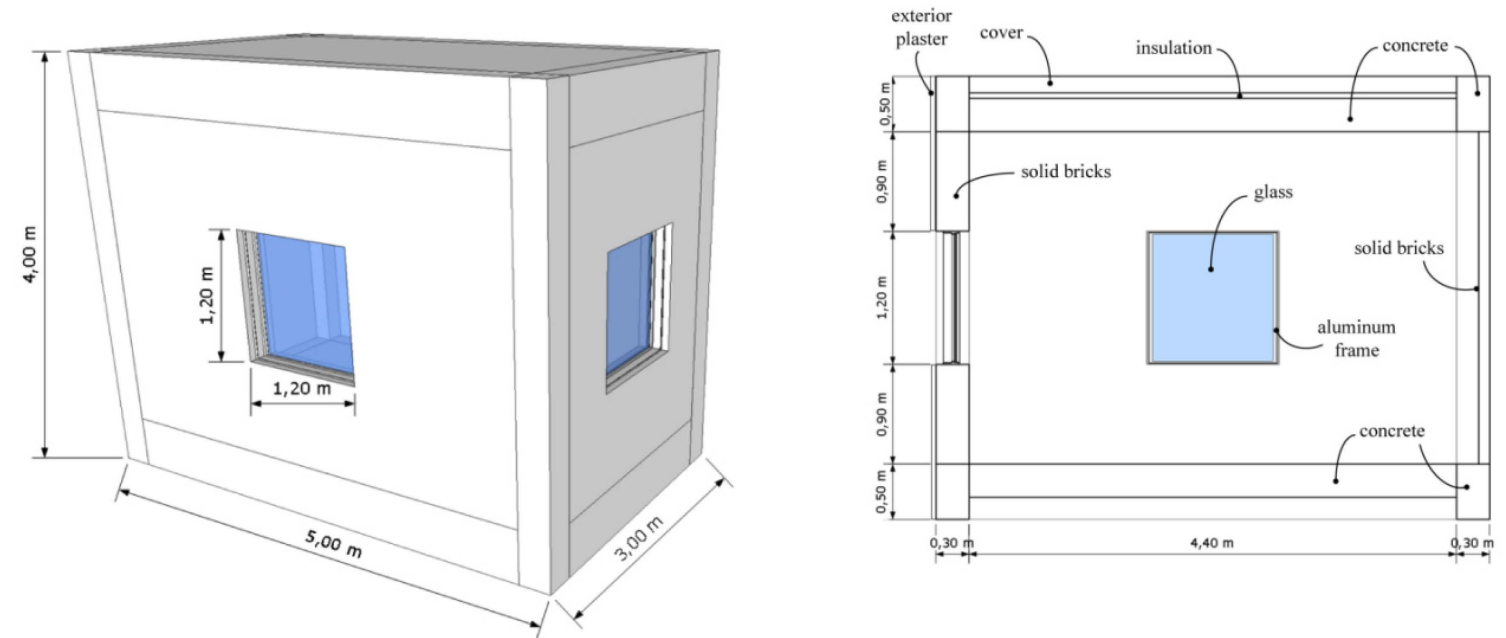

Figure 14. Geometrical characteristics of the room envelope: three-dimensional view (left); longitudinal section in correspondence of the window (right). 
This configuration could be considered representative of the actual behavior of a building envelope. In the authors' opinion, the present 3D microscopic numerical approach should be used in order to evaluate local heat and mass transfer phenomena, while lumped parameter models could be used to reproduce the global behavior of building envelopes. The properties of the solid bricks, insulation material, concrete and plaster are those reported in Table 3. As concerns the other materials used in the simulations carried out in this section, the physical properties, taken from the technical standard [12], are reported in Table 5.

Table 5. Properties of the materials employed in the room envelope.

\begin{tabular}{|c|c|c|c|c|}
\hline Material & $\begin{array}{c}\text { Thermal } \\
\text { Conductivity } \\
\lambda \\
(\mathbf{W} /(\mathbf{m} \cdot \mathbf{K}))\end{array}$ & $\begin{array}{c}\text { Vapor } \\
\text { Permeability } \\
\delta \cdot 10^{12} \\
(\mathbf{k g} /(\mathbf{m} \cdot \mathbf{s} \cdot \mathbf{P a}))\end{array}$ & Density & $\begin{array}{c}\text { Heat Capacity } \\
\boldsymbol{c} \\
(\mathbf{J} /(\mathbf{k g} \cdot \mathbf{K}))\end{array}$ \\
\hline Cover & 1.5 & 3.0 & 2100 & 1000 \\
\hline Glass & 1.0 & 0.0 & 2500 & 750 \\
\hline Aluminum frame & 160 & 0.0 & 2800 & 880 \\
\hline
\end{tabular}

Figure 15 shows the temperature contours in the room envelope obtained at four different times $(12,48,96$ and $168 \mathrm{~h})$. From the analysis of this figure, it is evident that the minimum temperatures of the interior side of the envelope are calculated in correspondence of the thermal bridges, and in particular at the corner between the exterior walls.

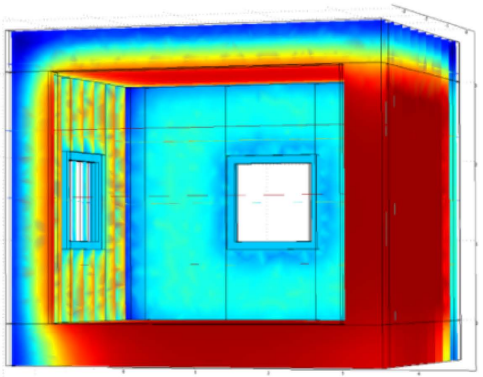

a)

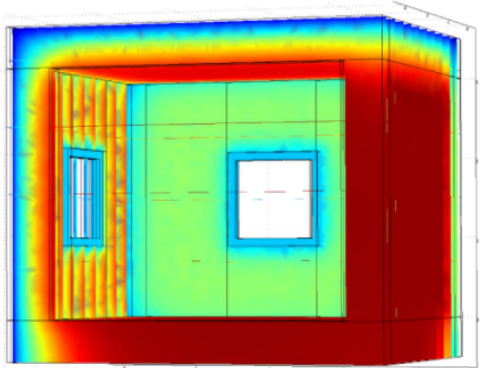

c)
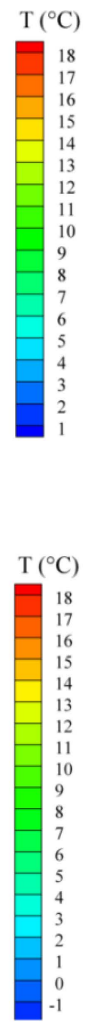

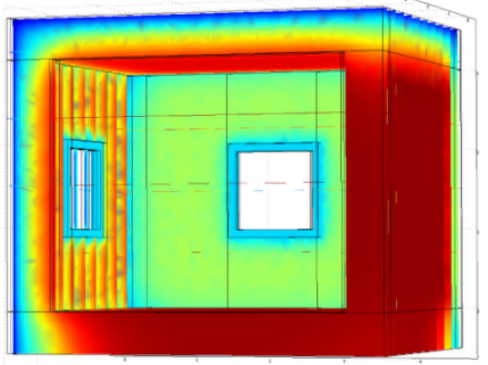

b)
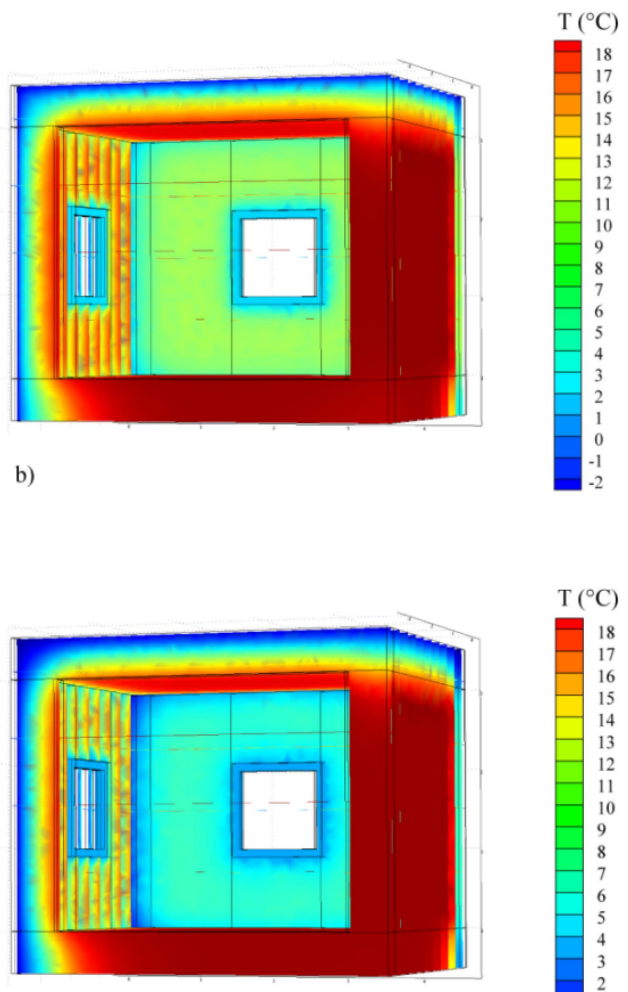

d)

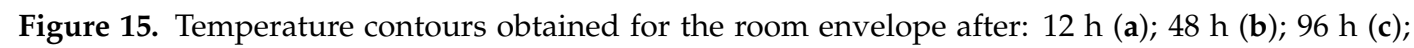
$168 \mathrm{~h}$ (d).

Figure 16 shows the variation of temperature and pressure difference over time at points A and B represented in Figure 17. The results reported in Figure 16 clearly show that the corner between walls, 
pillar and roof (point A) is the critical point of the envelope, as expected. In fact, the temperature values at point $A$ are significantly smaller than those of point $B$ during the whole week. As a consequence, the difference between partial pressure of vapor and saturation pressure of water assumes values greater than zero after about $105 \mathrm{~h}$. This means that condensation occurs at the corner (point A), as expected, but not at point $B$.
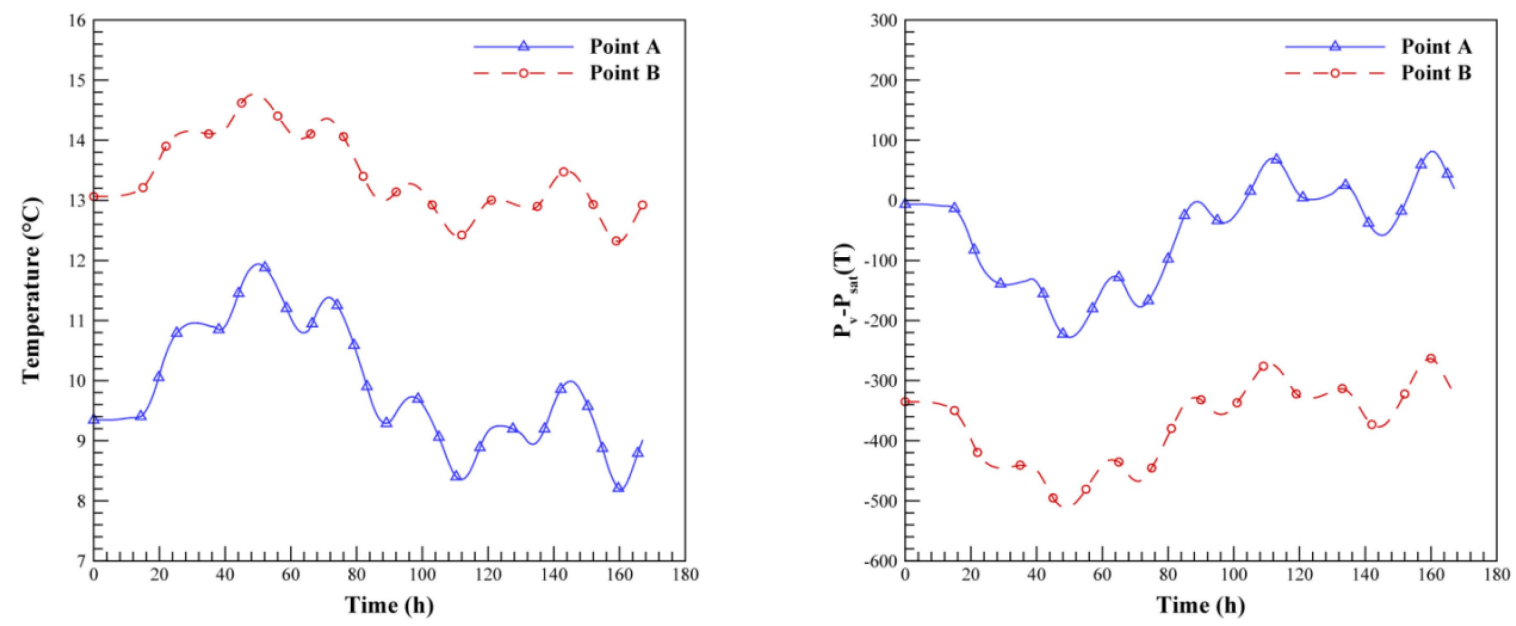

Figure 16. Temperature (left) and difference between partial pressure of water vapor and saturation pressure of water (right) at points A and B of Figure 17.

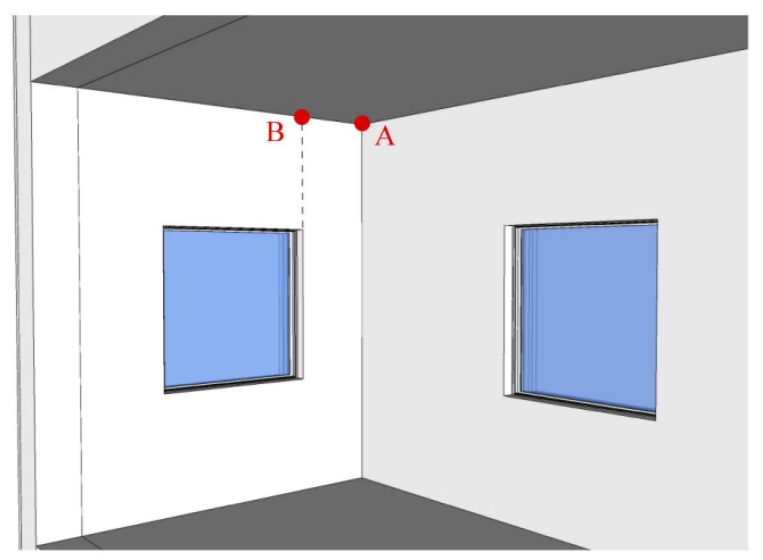

Figure 17. Particular of the room envelope. Point $\mathbf{A}$ is the corner between walls, pillar and roof, while point $\mathbf{B}$ is a point at the corner between wall and roof in correspondence of the window's side.

\section{Conclusions}

In this work, the authors solve steady-state and unsteady conduction heat transfer and vapor diffusion in three-dimensional (3D) inhomogeneous thermal bridges, by using the finite element method. The authors highlight the importance of using a microscopic approach to take into account the inhomogeneities present in structures commonly employed in building envelopes, such as steel-concrete pillars or brick-concrete slabs, in order to estimate heat losses and water condensation in $3 \mathrm{D}$ thermal bridges and room envelopes. Both steady-state and unsteady simulations show that the heat flux transferred by 3D thermal bridges and the condensed water can be significantly different if the inhomogeneities in the materials are considered. Steady-state simulations can be useful during a first design stage, while transient ones are required for a proper design or as support to the management and control of heating/cooling systems. The main results obtained in the present paper can be summarized as follows: 
- The heat flux transferred through the considered 3D thermal bridge assumes a value greater than $16 \%$, when the presence of inhomogeneities in the employed materials is considered by using the present microscopic approach;

- The water condensed in the 3D thermal bridge considered is greater than $12 \%$, when the presence of inhomogeneities in the employed materials is considered by using the present microscopic approach;

- Critical regions of building envelops, in terms of hygrothermal behavior, can be identified by using the present 3D numerical approach.

The authors think that the use of the present microscopic approach to take into account the inhomogeneities inside construction materials could lead to a reduction of the uncertainties in the estimation of thermal bridges' contribution in building structures. The present microscopic approach allows us to simulate heat and mass transfer in 3D thermal bridges and to highlight critical local phenomena in building envelopes. The present 3D numerical approach can be a useful tool for the energy certification of buildings, especially in their design stage, and could be used together with lumped parameter models that are capable of reproducing the global behavior of entire buildings.

Author Contributions: All the authors have contributed to the preparation of this manuscript.

Conflicts of Interest: The authors declare no conflict of interest.

\section{Nomenclature}

$\begin{array}{ll}c & \text { Specific heat }(\mathrm{J} /(\mathrm{kg} \cdot \mathrm{K})) \\ g_{v} & \text { Diffusive vapor flux }(\mathrm{g} / \mathrm{s}) \\ g_{\text {sat }} & \text { Diffusive vapor flux at saturation condition }(\mathrm{g} / \mathrm{s}) \\ h_{c} & \text { Convective heat transfer coefficient }\left(\mathrm{W} /\left(\mathrm{m}^{2} \cdot \mathrm{K}\right)\right) \\ \dot{m}_{w} & \text { Rate of condensed water }(\mathrm{g} / \mathrm{s}) \\ n & \text { Unit vector in normal direction } \\ p_{v} & \text { Partial pressure of vapor }(\mathrm{Pa}) \\ p_{\text {sat }}(T) & \text { Saturation pressure of water at temperature } T(\mathrm{~Pa}) \\ s & \text { Thickness }(\mathrm{m}) \\ T & \text { Temperature }(\mathrm{K})\end{array}$

Greek symbols

$\begin{array}{ll}\delta & \text { vapor permeability } \\ \lambda & \text { Thermal conductivity } \\ \rho & \text { Density }\left(\mathrm{kg} / \mathrm{m}^{3}\right) \\ \vartheta & \text { Time }(\mathrm{s}) \\ \text { Subscripts } & \\ \infty & \text { Air/Environment } \\ 0 & \text { Initial } \\ b & \text { Bricks } \\ c o & \text { Concrete } \\ e & \text { Exterior } \\ i & \text { Interior } \\ P & \text { Point on the surface } \\ s & \text { Steel } \\ v & \text { Vapor } \\ w & \text { Water }\end{array}$


$x$

$y$

$z$

$\mathrm{x}$-direction
$\mathrm{y}$-direction
$\mathrm{z}$-direction

\section{References}

1. Tadeu, A.; Simões, I.; Simões, N.; Prata, J. Simulation of dynamic linear thermal bridges using a boundary element method model in the frequency domain. Energy Build. 2011, 43, 3685-3695. [CrossRef]

2. Energy efficiency: energy Performance of Buildings. Directive 2002/91/EC. 2002.

3. Energy End-Use Efficiency and Energy Services and Repealing Council Directive 93/76/EEC. Directive 2006/32/EC. 2006.

4. Energy Performance of Buildings. Directive 2010/31/EC. 2010.

5. Rendimento Energetico in Edilizia. Directive D.P.R. 02/04/2009 n.59. 2009.

6. Hygrothermal performance of building components and building elements-Internal surface temperature to avoid critical surface humidity and interstitial condensation-Calculation methods. UNI EN ISO 13788:2003. 2003.

7. Theodosiou, T.G.; Papadopoulos, A.M. The impact of thermal bridges on the energy demand of buildings with double brick wall constructions. Energy Build. 2008, 40, 2083-2089. [CrossRef]

8. Thermal bridges in building construction-Linear thermal transmittance-Simplified methods and default values. UNI EN ISO 14683:2001. 2001.

9. Thermal bridges in building construction-Heat flows and surface temperatures-detailed calculation. UNI EN ISO 10211:2008. 2008.

10. Magrini, A.; Magnani, L.; Pernetti, R. The effort to bring existing buildings towards the A class: A discussion on the application of calculation methodologies. Appl. Energy 2012, 97, 438-450. [CrossRef]

11. Materiali da costruzione-Conduttività termica e permeabilità al vapore. UNI 10351:1994. 1994.

12. Building materials and products-Hygrothermal properties-Tabulated design values. UNI EN 12524:2001. 2001.

13. Building materials and products-Hygrothermal properties-Tabulated design values and procedures for determining declared and design thermal values. UNI EN ISO 10456:2008. 2008.

14. Martin, K.; Erkoreka, A.; Flores, I.; Odriozola, M.; Sala, J.M. Problems in the calculation of the thermal bridges in dynamic conditions. Energy Build. 2011, 43, 529-535. [CrossRef]

15. Quinten, J.; Feldheim, V. Dynamic modelling of multidimensional thermal bridges in buildingenvelopes: Review of existing methods, application and new mixed method. Energy Build. 2016, 110, 284-293. [CrossRef]

16. Gao, Y.; Roux, J.J.; Zhao, L.H.; Jiang, Y. Dynamical building simulation: A low order model for thermal bridges losses. Energy Build. 2008, 40, 2236-2243. [CrossRef]

17. Kosny, J.; Christian, J.E. Thermal evaluation of several configurations of insulation and structural materials for some metal stud walls. Energy Build. 1995, 22, 157-163. [CrossRef]

18. Kosny, J.; Kossecka, E. Multi-dimensional heat transfer through complex buildings envelope assemblies in hourly energy simulation programs. Energy Build. 2002, 34, 445-454. [CrossRef]

19. Mao, G.; Johannesson, G. Dynamic calculation of thermal bridges. Energy Build. 1997, 26, 233-240. [CrossRef]

20. Déqué, F.; Ollivier, F.; Roux, J.J. Effect of 2D modelling of thermal bridges on the energy performance of buildings: Numerical application on the Matisse apartment. Energy Build. 2001, 330, 583-587. [CrossRef]

21. He, J.; Hoyano, A.; Asawa, T. A numerical simulation tool for predicting the impact of outdoor thermal environment on building energy performance. Appl. Energy 2009, 86, 1596-1605. [CrossRef]

22. Theodosiou, T.G.; Tsikaloudaki, A.G.; Kontoleon, K.J.; Bikas, D.K. Thermal bridging analysis on cladding systems for building facades. Energy Build. 2015, 109, 377-384. [CrossRef]

23. Nussbaumer, T.; Wakili, K.G.; Tanner, C. Experimental and numerical investigation of the thermal performance of a protected vacuum insulation system applied to a concrete wall. Appl. Energy 2006, 83, 841-855. [CrossRef]

24. Wakili, K.G.; Simmler, H.; Frank, T. Experimental and numerical thermal analysis of a balcony board with integrated glass fibre reinforced polymer GFRP elements. Energy Build. 2007, 39, 76-81. [CrossRef]

25. Zalewski, L.; Lassue, S.; Rousse, D.; Boukhalfa, K. Experimental and numerical characterization of thermal bridges in prefabricated building walls. Energy Convers. Manag. 2010, 51, 2869-2877. 
26. Lorenzati, A.; Fantucci, S.; Capozzoli, A.; Perino, M. Experimental and numerical investigation of thermal bridging effects of jointed Vacuum Insulation Panels. Energy Build. 2016, 111, 164-175. [CrossRef]

27. Mauro, A.; Arpino, F.; Massarotti, N.; Nithiarasu, P. A novel single domain approach for numerical modelling solid oxide fuel cells. Int. J. Numer. Methods Heat Fluid Flow 2010, 20, 587-612. [CrossRef]

28. Mauro, A.; Arpino, F.; Massarotti, N. Three-dimensional simulation of heat and mass transport phenomena in planar SOFCs. Int. J. Hydrogen Energy 2011, 36, 10288-10301. [CrossRef]

29. Arpino, F.; Massarotti, N.; Mauro, A. Efficient three-dimensional FEM based algorithm for the solution of convection in partly porous domains. Int. J. Heat Mass Transf. 2011, 54, 4495-4506. [CrossRef]

30. Carotenuto, A.; Massarotti, N.; Mauro, A. A new methodology for numerical simulation of geothermal down-hole heat exchangers. Appl. Therm. Eng. 2012, 48, 225-236. [CrossRef]

31. Zienkiewicz, O.C.; Taylor, R.L.; Nithiarasu, P. The Finite Element Method for Fluid Dynamics, 6th ed.; Elsevier Butterworth-Heinemann: Oxford, UK, 2005.

32. Lewis, R.W.; Nithiarasu, P.; Seetharamu, K.N. Fundamentals of the Finite Element Method for Heat and Fluid Flow; John Wiley \& Sons: Chichester, UK, 2004.

33. Ficker, T. Non-isothermal steady-state diffusion within Glaser's condensation model. Int. J. Heat Mass Transf. 2003, 46, 5175-5182. [CrossRef]

34. Vydra, V. Degradation risk assessment of external envelopes: A practical engineering approach. Build. Environ. 2007, 42, 344-348. [CrossRef]

35. Building components and building elements-Thermal resistance and thermal transmittance-Calculation method. UNI EN ISO 6946:2008. 2008.

36. Regolamento recante norme per la progettazione, l'installazione, l'esercizio e la manutenzione degli impianti termici degli edifici ai fini del contenimento dei consumi di energia. Directive D.P.R. 26/10/1993 n.412. 1993.

37. Energy performance of buildings-Part 1: Evaluation of energy need for space heating and cooling. UNI/TS 11300-1:2008. 2008.

38. Heating systems in buildings-Method for calculation of the design heat load. UNI EN 12831:2006. 2006.

39. Colangelo, F.; Ferone, C.; De Luca, G.; Mauro, A. Experimental and Numerical Analysis of Thermal and Hygrometric Characteristics of Building Structures Employing Recycled Plastic Aggregates and Geopolymer Concrete. Energies 2013, 6, 6077-6101. [CrossRef]

40. Hygrothermal performance of buildings-Calculation and presentation of climatic data Part 4: Hourly data for assessing the annual energy use for heating and cooling. UNI EN ISO 15927-4:2005. 2005.

(C) 2016 by the authors; licensee MDPI, Basel, Switzerland. This article is an open access article distributed under the terms and conditions of the Creative Commons by Attribution (CC-BY) license (http:/ / creativecommons.org/licenses/by/4.0/). 